\title{
Study on the audit risk under the environment of e-commerce
}

\author{
Yunji Liang ${ }^{1, a}$, Lijun Bu ${ }^{2, b}$ \\ ${ }^{1}$ School of Accounting, Harbin University of Commerce, Harbin 150028, China; \\ 2 School of Accounting, Harbin University of Commerce, Harbin 150028, China. \\ a liangyunji@126.com, b bulijun@126.com
}

Keywords: E-commerce, Audit risk, Prevention and control Shock to distribution of international tax benefit by e-commerce.

\begin{abstract}
The emergence of e-commerce as a brand new subject has brought enormous changes to the economic environment that audit faces. This paper starts from the influence of e-commerce to auditing, and makes detailed analysis to the audit risks in e-commerce environment and at last it gives some prevention and control suggestions.
\end{abstract}

\section{An overview of e-commerce audit}

A. The concept of e-commerce

E-commerce has its broad and narrow sense. In broad sense, e-commerce refers to the electronization of all business in all industries, and it can also be called e-business, which includes e-government, e-health care, e- education, etc. In its narrow sense, e-commerce refers to the commercial activities that are carried out in electronic ways, and it can be called e-transaction, which includes e-shopping, e-payment, e-market, e-account, etc.

B. The impact of e-commerce to accounting

Virtual enterprise in e-commerce environment has changed the traditional production environment of tangible goods, and thus the accounting environment that the traditional accounting relies on has also changed. E-commerce has brought accounting that uses traditional bills for transferring to paperless e-accounting era, in which digital products have the characters of both tangible assets and intangible assets, and thus how to conduct accounting recognition to these products is a new problem that accounting encounters. These new accounting problems, such as paperless electronic data, e-cash, and network security have brought new risks and new tasks to audit.

C. The impact of e-commerce to audit

1) Impact on auditing targets

With the emergence of e-commerce, enterprises have strengthened their connection with the outer world unprecedentedly, the information users can gain more materials than before, and the importance of statement to information users has been lessened due to time limitation because what the users need are the latest information. All these require that the audit target shall not only include the traditional audit to statement, but also the audit to the vested interest of the relative shareholders of the enterprises.

2) Impact on the service objects of audit

The traditional audit objects are the financial balance and relative operation and management activities of an enterprise, but with the support of network, transnational and trans-regional audit is not difficult anymore, and programs such as e-certification, audit tests, etc, which are carried out via email have greatly quickened audit speed and expended audit scale. Because the business are becoming hidden and digital, corruptions are more likely to happen, which means that the audit targets are not only the validity and authenticity of the business, but also the accuracy of original vouchers that are typed in, the reliability of online accounting information system, the security of application system and data files, etc. With the addition of these audit targets, the audit risk is increasing accordingly.

3)Impact on audit methods 
The traditional accounting is carried out manually with a clear auditing clue. But in the e-commerce environment, it is accomplished automatically in computer, under the instruction of program. So it is quite difficult to trace the processing flow of an operation, which increased the risk of audit.

The traditional audit method is system audit, whose key point is the internal control of the enterprise. While under e-commerce environment, the rapidly changes of information technology and network technology make the uncertainties of the internal and external environment of an enterprise increase rapidly. As for internal environment, the control system which relies on computer technology is more complicated than manual controlled system; as for external environment, the more and more intense competition calls for audit to provide more timely, effective and comprehensive information. This requires that the traditional post-audit and site-audit methods shall be changed to online real-time auditing method, so that audit evidences could be collected timely and audit risks shall be reduced.

4)Impact on the quality of auditing staff

With the changes of auditing environment, content and technology, e-commerce audit ask for a higher requirement to auditing staff, because auditing staff, without knowledge on computer, network and e-commerce, will be unable to conduct audit with the auditing clue changed, unable to distinguish and evaluate audit risks, and unable to audit the function and developing of information system.

\section{Audit risk in e-commerce}

\section{A. Inherent risks}

Inherent risks refer to the possibilities of there being severe mistakes or missed reports in some accounts or transactions without considering internal controls. Traditional inherent risks are mainly due to the mistakes or illegal activities of business transactions in financial statement, and are only related to the audited department or their environment, irrelevant to the auditors. So the auditing staff can not reduce the inherent risks. Besides, the inherent risks in e-commerce also include:

1)The auditing clue is very difficult to trace

In traditional business activities, every transaction has written record and signature of relative person, which makes it easy for the auditors to trace forward and backward according to the accounting process. But in e-commerce system, original vouchers such as invoices, checks, material requisitions and warehousing entries are transferred through the internet in the form of electromagnetic information. The information system will draw up accounting voucher, register books of account and make statement automatically according to the verified business transactions. Having only results, but no clues, and each process having no direct person in charge, the auditors don't know where to start tracing, and the possibilities for them to make wrong audit conclusion will increase.

2) Electronic data are very easily to be attacked

Under internet operation circumstance, enterprise operation and assets security can no longer be solved by enterprise internal control. The opened internet exposes electronic data in the risk of being distorted or get lost, and once hackers entered the internet system, the data may be distorted without any trace. Even in computer system, some documents and vouchers shall be typed manually, in which case mistakes and omissions are likely to occur, and besides, e-signature, unlike hand-written signature, is difficult to be identified for legal purpose. All the above mentioned conditions will increase the inherent risks.

\section{B.Control risk}

Control risk refers to the possibility of there being some misstatements or missed reports in some accounts without being discovered or rectified via internal control. Traditional control risks are related to internal control, while the control risks in e-commerce are mainly in:

1)Restraining mechanism being out of control

In the manual accounting system, each section of business transaction has the signature of the person in authority. While in computer system, different functional modules are divided for separate 
management, or passwords are set for the division of labor. Some people may get the passwords or ciphers beyond their authority, for example, by illegally obtaining other's password, the business people will provide sales and delivery bills without permission; or they will get the password of clients' orders, place fake orders and defraud the company's products.

2)The imperfection of the software will cause the data abnormal or wrong

It may happen in internet accounting that business transaction is correct and there is no human fault, but because of program errors or security flaws in system, false results may emerge in the program running, which will affect the statement correctness, especially in the highly integrated business administrative software.

\section{C.Checking risk}

Checking risk refers to the possibility of there being some misstatements or missed reports in some accounts without being discovered in substantive testing. The checking risks in e-commerce are mainly in: since the audit evidences in e-commerce are from internet system whose reliability relies on the integrity and viability of network internal control system, so it is very difficult for the auditors to judge the fairness of business and statement just by routine testing program. So the auditors shall audit not only the authenticity and legality of the data emerged in e-commerce activities, but also the security and reliability of e-commerce system. Especially with the update of software version, the correctness of the data in previous year makes the audit risks even more uncontrollable.

\section{Preventive and controlling measures to audit risks in e-commerce}

A. Measures to reduce inherent risks

1)Improve soft ware and hard ware

Add Fire Wall and strengthen information encryption; set up compulsive backups in software setting, otherwise the next work shall not be carried out; the number-picking formula of statement shall not be modified without permission; digital signature shall be adopted to verify the identity of the opposite side and to ensure the data completeness; improve data entry technology, and scanning technology can be used in electronic data processing to reduce mistakes in typing; use automatic account transferring function whenever it is possible to ensure the completeness and correctness of the data.

2)Improve the auditors' quality

In order to work well under internet environment, besides knowledge on accounting, audit, economy, management, law, and other knowledge used in traditional operation condition, the auditors shall also master knowledge and technology on computer, internet, information system, e-commerce, etc. They shall master the characteristics of internet operation and internet accounting, the necessary control and audit methods, and use auditing software skillfully to conduct audit on computer.

B.Some measures to reduce control risks

Personnel in each position shall work within their own limits of authority, and to approach the system beyond one's limit of authority is forbidden. The password of the system shall be long enough and be changed frequently; all the users shall change their passwords regularly, so that the system cannot be operated ultra vires for the safety of the system; in using important materials in computer, the entering program shall be strict enough; the modified files and data shall have records for future reference; all the vouchers and data shall be backed up compulsively, and the back-ups shall be kept by different person, so that internal checking system could be established. The auditors shall carry out real-time tracing to the relative internet with audit software, examine the discrepant data in great detail, and warn the abnormal transaction to reduce the audit risks.

C.Measures to reduce check risks

In picking up and storing data of different years, on one hand, software industry standard shall be established, and on the other hand, the departments to be audited shall adopt unified form to store the accounting software of different versions. To avoid audit risks, the network hardware and software functions, such as compatibility, the rationality of the program design, the validity of control and 
managing function, the comprehensiveness of system testing, the integrity of files and materials, and the expending extent of the system, shall be analyzed systematically, and the controlling condition of internal enterprise shall be known. Carry out substantive testing to original materials, examine and check each important business, verify and analyze them with electronic data, test the correctness of original vouchers, and of posting and summarizing, check whether the items of account in every sub system of computer system are correspondence with each other, send emails to internet banking center, clients and suppliers for confirmation and audit evidence.

\section{References}

[1]. Jagdish Pathak,Amelia Baldwin.Audit Resource Planning Success in B2B E-Commerce: Development and Testing of a Measurement Scale[J]. Information Systems Management, 2008, Vol.25 (3)

[2]. Chen Wanling, A Primary Exploration Into Auditing under the Environment of Internet Operation and Internet Accounting [J].Accounting Research, 2009, (5)

[3]. Zhang Hongying, A Primary Exploration into Internet Auditing [J].Finance and Accounting Study, 2010, (6)

[4]. Bunget Ovidiu-Constantin,Dumitrescu Alin-Constantin,Dreve Raluca-Madalina.Risk Management's importance and role in audit [J].Annals of the University of Oradea : Economic Science, 2010, Vol.1 (1):484

[5]. Yumei Wang,Man Li.The Role of Internal Audit in Engineering Project Risk Management[J]. Procedia Engineering,2011, Vol.24:689-694 